\title{
A COMPARISON OF SINGLE-PORT LAPAROSCOPICALLY ASSISTED VAGINAL HYSTERECTOMY USING TRANSUMBILICAL SILS PORT ACCESS AND THREE-PORT LAPAROSCOPICALLY ASSISTED VAGINAL HYSTERECTOMY
}

\author{
Seong Nam Park, MD', Gi Youn Hong, MD¹, Hoon Young Kim, MD', Byoung Ryun Kim, MD', Cheol Lee, MD² \\ Departments of ${ }^{1}$ Obstetrics and Gynecology, ${ }^{2}$ Anestheology and Pain Medicine, University of Wonkwang College of Medicine, lksan, Korea
}

\section{Objective}

The purpose of this study was to compare surgical outcomes and patients' satisfaction between single-port access laparoscopically assisted vaginal hysterectomy (SPA-LAVH) and conventional three-port access LAVH (TPA-LAVH) group.

\section{Methods}

A prospective analysis was performed in patients who underwent laparoscopically assisted vaginal hysterectomy at a Wonkwang University Hospital between April 2010 and May 2011, a total of 138 women were enrolled in this study. One of these procedures was chosen by patient and was performed with their consent. Sixty-five women underwent SPA-LAVH using transumbilical SILS port access (SPA-LAVH group), and 73 women underwent conventional three-port LAVH (TPA-LAVH group).

\section{Results}

There were no statistical differences between groups in the patients' demographic characteristics, mean operating time $(93.4 \pm 20.2$ minutes vs. $95.1 \pm 28.7$ minutes, $P=0.696)$, postoperative changes in hemoglobin concentration $(1.91 \pm 0.68 \mathrm{vs} .1 .85 \pm 0.87 \mathrm{~g} / \mathrm{dL}$, $P=0.667)$, weight of the resected uterus $(261.7 \pm 205.3 \mathrm{~g}$ vs. $311.8 \pm 268.3 \mathrm{~g}, P=0.225)$, hospital stay $(5.9 \pm 0.9$ day vs. $6.4 \pm 1.6$ day, $P=0.063)$, the rate of using an additional trocar (1.5\% vs. $0 \%, P=0.471)$, the rate of conversion to laparotomy $(0 \%$ vs. $4.1 \%$, $P=0.098$ ) and postoperative pain scores (visual analogue scale) for 48 hours. However, patients' satisfaction after 6 weeks later was significantly greater in SPA-LAVH group than in conventional group, as evidenced by higher rate of fairly satisfactory $(52.3 \%$ vs. $34.2 \%, P=0.032)$ and very satisfactory $(33.8 \%$ vs. $17.8 \%, P=0.031)$.

\section{Conclusion}

SPA-LAVH using transumbilical SILS port access is comparable with TPA-LAVH in women undergoing LAVH. However, SPA-LAVH is better than TPA-LAVH in terms of satisfaction of patient.

Keywords: Single-port access; Three-port access; Laparoscopically assisted vaginal hysterectomy; Patients' satisfaction

자궁절제술은 세계적으로 부인과 영역에서 가장 흔히 시행되는 수술 이다. 수술 방법은 크게 복식자궁절제술, 질식자궁절제술, 복강경하 질 식자궁절제술, 복강경하 전자궁절제술, 로봇수술로 시행되고 있다. 복 강경 자궁절제술은 1980 년대 말 처음으로 보고된 이후 급격한 복강경 장비와 수술 방법의 발달로 흔히 시행되는 방법이다[1,2].

1991년 Pelosi와 Pelosi [3]가 단일공법 복강경 자궁절제술을 시행한 이후, 흉터의 감소와 수술 후 통증을 줄이기 위하여 3 개 혹은 4 개의 포 트로 진행되는 기존의 복강경수술을 대체하여 다양한 형태의 단일공 법 복강경수술이 최근 부인과 분야에서 시행되고 있다. 단일공법 복강 경수술은 적은 감염, 짧은 재원일 수, 감소된 수술 합병증, 빠른 회복과
Received: 2011. 8.12. Revised: 2011.11.24. Accepted: 2011.12.9.

Corresponding author: Byoung Ryun Kim, MD

Department of Obstetrics and Gynecology, University of

Wonkwang College of Medicine, 344-2 Sinyong-dong, Iksan 570-749, Korea

Tel: +82-10-9425-3103 Fax: +82-63-852-7520

E-mail: brkim21@lycos.co.kr

This is an Open Access article distributed under the terms of the Creative Commons Attribution Non-Commercial License (http://creativecommons.org/licenses by-nc/3.0/) which permits unrestricted non-commercial use, distribution, and reproduction in any medium, provided the original work is properly cited.

Copyright $\odot$ 2012. Korean Society of Obstetrics and Gynecology 


\section{KOREAN JOURNAL OF OBSTETRICS \& GYNECOLOGY}

Seong Nam Park, et al. Single-port laparoscopically assisted vaginal hysterectomy

뛰어난 미용효과 등 여러 가지 장점이 보고되고 있다[3-7].

현재 단일공법 복강경하 질식자궁절제술은 고식적 방법에 견줄만하 거나 수술 후 통증에서 더 좋다는 결과들이 보고되고 있으며[5-8], 글 러브와 상처견인기를 이용한 방법부터 다양한 단일공법 기구들을 이용 하여 시행되고 있는바 저자들은 SILS 포트를 이용한 단일공법 복강경 하 질식자궁절제술의 유용성과 안전성, 수술 6주 후 환자 만족도를 평 가하기 위해 본 연구가 시행되었다.

\section{연구대상 및 방법}

2010년 4월부터 2011년 5월까지 원광대학교병원 산부인과를 내원 하여 자궁절제술을 시행된 환자들 중 1 인의 의사에게 자궁경부와 자궁 체부의 양성질환으로 복강경하 질식자궁절제술이 시행된 총 138명의 환자들을 대상으로 의무기록지를 분석하였다. 의무기록지에서 나이, 체중, 키, 분만력, 수술 과거력, 과거병력을 조사하였다. 수술시간은 피 부절개부터 봉합까지로 하였고, 수술 후 발열은 첫 24시간을 제외하고 $38^{\circ} \mathrm{C}$ 이상의 체온이 4 시간 간격으로 두 번 이상인 경우로 정의하였다. 혈색소변화는 수술 전 혈색소 수치와 수술 후 1일째 혈색소 수치를 비 교하였다. 수술 후 통증은 시각통증등급(visual analogue scale) [9]을 이용하여 수술직후, 6 시간, 24시간, 48시간 후에 측정하였다. 환자 만 족도는 수술 6 주 후 외래 진찰하면서 수술에 대한 만족도를 조사한 자 료를 분석하였다. 만족도는 매우 만족, 만족, 보통, 불만족으로 분류하 여 1 인의 의사에 의해 조사되었다.

모든 환자들에게 단일공법과 삼공법 복강경하 질식자궁절제술의 장 점과 단점이 설명되었고 수술방법은 환자들이 직접 선택하였으며, 본 원의 임상시험심사위원회의 승인 후 시행되었다.

수술은 전신마취 후, 환자 왼쪽 팔은 수술자의 행동반경에 방해되지 않도록 몸에 붙이고, 쇄석위 자세를 취하였다. 수술자는 환자의 왼쪽 에, 제 1 수술보조자는 환자의 오른쪽에, 제 2 수술보조자는 환자의 하부
에 위치하였다. 소변 도뇨를 위해 $18 \mathrm{~F}$ 방광 도뇨관을 삽입하고, 자궁 거상기를 삽입하였다.

단일공법 복강경하 질식자궁절제술을 시행 받는 환자들은 먼저 배꼽 을 일부 절개하여 앨리스 겸자(Allis forceps)로 잡고 들어 올려 배꼽 정 중선에 $1.5 \mathrm{~cm}$ 길이의 수직절개를 실시한 후, $2.0 \mathrm{~cm}$ 정도의 근막절개 술을 시행하여 복강내 통로를 확보하였다. 가스흡입 채널과 3 개의 관 을 가지는 SILS 포트(SILS Port, Covidien, Mansfield, MA, USA)의 하단 부에 젤리를 바른 후 켈리 겸자를 이용하여 배꼽 통로에 삽입하고 3개 의 관을 삽입하였다(Fig. $1 \mathrm{~A}$ ). 복강경수술에 필요한 $\mathrm{CO}_{2}$ 가스는 가스흡 입채널을 통하여 $12 \mathrm{~mm} \mathrm{Hg}$ 압력이 되도록 불어 넣어졌다. 환자는 $30^{\circ}$ 정도 트렌델렌버그 체위(Trendelenburg position)를 취하였다. 일직선 $5 \mathrm{~mm} 0^{\circ}$ 내시경을 삽입하였고 구부러지지 않는 $5 \mathrm{~mm}$ 의 복강경 기구 들과 혈관전용 전기수술기(LigaSure Vessel Sealing System, Covidien, Valleylab, CO, USA)을 사용하여 고식적 복강경하 질식자궁절제술과 같은 방법으로 골반누두인대 또는 난소인대와 자궁광인대를 절개하였 다. 자궁상부와 방광은 단극성 전기소작기를 이용하여 박리하였다. 절 제된 질상부는 2-0 polysorb 봉합사로 봉합하고 복막과 근막을 2-0 polysorb 봉합사로 봉합하였고 피부는 3-0 polysorb 봉합사로 표피밑 봉합(subcuticular suture)한 후 수술을 마쳤다(Fig. 1B). 삼공법 복강경 하 질식자궁절제술은 1 개의 $10 \mathrm{~mm}$ 포트와 2 개의 $5 \mathrm{~mm}$ 포트를 사용 하여 단일공법과 같은 방법으로 수술을 시행하였다.

통계적 분석은 Shapiro-Wilk test를 통해 연속형 변수(나이, 체질량 지수, 분만력, 수술시간, 절제된 자궁무게, 혈색소변화, 재원기간, 수술 후 통증)들의 변수들이 정규분포를 이루어 Student's $t$-test를 시행하 였고, 범주형 변수(수술 과거력, 골반유착, 합병증, 추가적 포트 및 개 복술로의 전환, 수혈, 수술 후 발열, 환자 만족도)들을 비교하기 위해 Fisher's exact test 또는 chi-square test를 시행하였다. 모든 자료는 평균 \pm 표준편차 또는 숫자 $\%)$ 로 표기하였다. 모든 경우 $P$ 값이 0.05 미 만인 경우 통계학적으로 유의하다고 평가하였다.
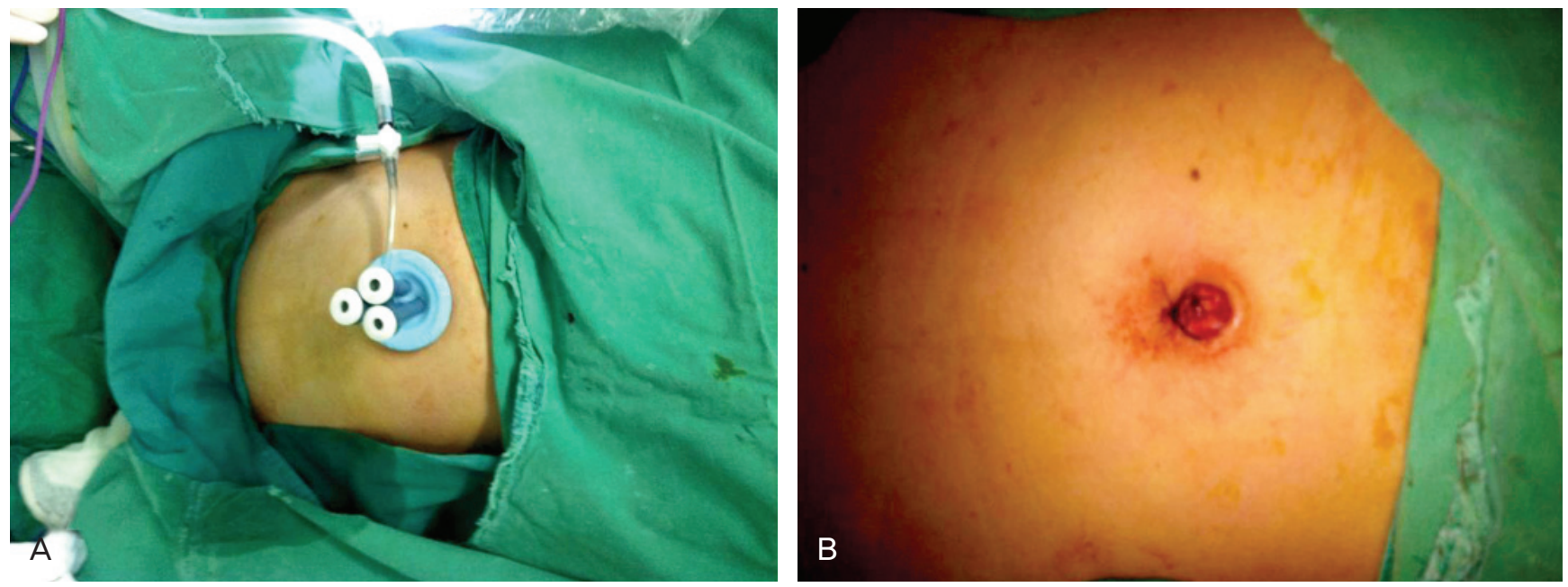

Fig. 1. (A) SILS port was placed in the umbilicus. (B) Photograph of umbilicus after skin suture. 


\title{
KOREAN JOURNAL OF OBSTETRICS \& GYNECOLOGY
}

\author{
KJOG Vol. 55, No. 1, 2012
}

\section{결 과}

2010년 4월부터 2011년 5월까지 SLLS 포트를 이용한 단일공법 복 강경하 질식자궁절제술(single-port access laparoscopically assisted vaginal hysterectomy)을 시행받은 65 명과 기존의 삼공법 복강경하 질 식자궁절제술(three-port access laparoscopically assisted vaginal hysterectomy)을 시행받은 73 명, 총 138명의 환자가 대상이 되었다.

단일공법과 삼공법 두 군 간의 임상적 특징은 각각 나이 $(46.7 \pm 4.5$ 세 vs. $47.3 \pm 7.9$ 세, $P=0.60)$, 분만력 $(2.1 \pm 0.7,2.2 \pm 1.1, P=0.60)$, 체질량 지수 $\left(24.60 \pm 3.08 \mathrm{~kg} / \mathrm{m}^{2}\right.$ vs. $\left.25.76 \pm 4.18 \mathrm{~kg} / \mathrm{m}^{2}, P=0.069\right)$, 수술 과 거력(26.2\% vs. $37.0 \%, P=0.173)$ 으로 두 군 간에 통계학적 차이는 없 었다-(Table 1).

단일공법과 삼공법 두 군 간의 수술시간(93.4 \pm 20.2 분 vs. $95.1 \pm 28.7$ 분, $P=0.696)$, 혈색소변화 $(1.91 \pm 0.68 \mathrm{~g} / \mathrm{dL}$ vs. $1.85 \pm 0.87$ $\mathrm{g} / \mathrm{dL}, P=0.667)$, 자궁 무게 $(261.7 \pm 205.3 \mathrm{~g}$ vs. $311.8 \pm 268.3 \mathrm{~g}$, $P=0.225)$, 재원기간(5.9 \pm 0.9 일 vs. $6.4 \pm 1.6$ 일, $P=0.063)$, 골반유착률 (18.5\% vs. $30.1 \%, P=0.112$ ), 추가적인 포트삽입(1.5\% vs. $P=0.471$ ), 개 복술로의 전환(0\% vs. 4.1\%, $P=0.098)$ 은 통계학적 차이는 없었다. 수 술과 연관된 합병증으로 수혈, 방광 및 요관의 손상, 장 손상, 수술 후 발열도 통계학적 차이는 없었다(Table 2).

수술 후 통증은 시각통증등급으로 수술 직후, 6시간, 24시간, 48시간 후 측정하였다. 단일공법과 삼공법 두 군은 각각 수술 직후 $(3.75 \pm 0.77$ vs. $3.54 \pm 0.85, P=0.140), 6$ 시간( $2.78 \pm 0.73$ vs. $2.56 \pm 0.71$, $P=0.072), 24$ 시간( $1.87 \pm 0.57$ vs. $1.90 \pm 0.60, P=0.787), 48$ 시간 $(1.53 \pm 0.53$ vs. $1.54 \pm 0.58, P=0.921)$ 으로 통계학적 차이는 없었다 (Table 3).

환자 만족도는 매우 만족, 만족, 보통, 불만족으로 분류하여 수술 6 주 후 외래 진찰 시 조사되었다. 단일공법과 삼공법 두 군 간 불만족 (1.5\% vs. $6.8 \%, P=0.127)$ 은 통계학적 차이가 없지만, 보통(12.3\% vs. $41.1 \%, P=0.000)$ 은 삼공법에서 유의하게 높았고, 만족(52.3\% vs $34.2 \%, P=0.032)$ 과 매우 만족(33.8\% vs. $17.8 \%, P=0.031)$ 은 단일공 법에서 통계학적으로 유의하게 높았다(Table 4).

\section{고 찰}

기존의 복강경수술은 3 개 혹은 4 개의 포트를 삽입하여 시행되는데, 최소 침습수술은 외과적 질환을 효과적으로 치료하면서 수술과 관련된 유병률과 침습성을 줄이는 것으로, 이러한 목적을 달성하기 위하여 복 부 절개의 숫자를 줄이거나 절개를 완전히 없애는 것을 제안하여 왔다 [10]. Pelosi와 Pelosi [3]는 기존의 방법이 아닌 수술 흉터와 수술 후 통증을 최소화할 수 있는 최소 침습수술을 소개하였다. 이들은 배꼽만 을 절개한 단일공법 복강경수술을 소개하였는데, 이러한 방법으로 질 식자궁절제술, 충수돌기절제술, 아전자궁절제술 등을 성공적으로 시행 하였다[3,11,12].

부인과 영역에서 단일공법 복강경수술은 적합한 것으로 보인다. 첫 째 질을 통한 접근이 가능하여 수술적 한계를 극복할 수 있고 질식 자 궁절제술이 용이하게 시행되며, 둘째 수술을 용이하게 자궁 조작기를 이용할 수 있고, 셋째 대부분 부인과 수술은 제거 수술로 광범위한 봉 합이나 문합이 필요하지 않고, 넷째 모든 환자들이 여자들로써 미용적 결과에 관심이 많아 명백한 미용효과의 장점이 있는 단일공법 복강경 수술은 매우 매력적이다[13].

현재 단일공법 복강경수술은 글러브와 상처견인기를 이용한 방법부 터 Uni-X System, Tri-port, Octo-port, SILS port와 같은 다양한 포트 시스템들과 구부러지는 기구들이 개발되어 이용되고 있는데 $[5,8,14-$ 16], 본 연구에서는 기존의 복강경 기구들과 작은 가스흡입채널과 5-12 mm의 관을 삽입할 수 있는 3개의 채널을 가진 SILS 포트를 사 용하였다. SILS 포트는 켈리를 이용하여 포트 하단부에 젤리를 발라서

Table 1. Patient characteristics

\begin{tabular}{|lcccc|}
\hline Characteristics & All $(\mathbf{n}=\mathbf{1 3 8})$ & SPA-LAVH $(\mathbf{n}=\mathbf{6 5})$ & TPA-LAVH $(\mathbf{n}=\mathbf{7 3})$ & $\boldsymbol{P}$-value \\
\hline Age $(\mathrm{yr})$ & $47.1 \pm 6.5$ & $46.7 \pm 4.5$ & $47.3 \pm 7.9$ & 0.600 \\
Parity & $2.1 \pm 0.9$ & $2.1 \pm 0.7$ & $2.2 \pm 1.1$ & 0.600 \\
BMI $\left(\mathrm{kg} / \mathrm{m}^{2}\right)$ & $25.21 \pm 3.74$ & $24.60 \pm 3.08$ & $25.76 \pm 4.18$ & 0.069 \\
No. of previous abdominal surgeries & $44(31.9)$ & $17(26.2)$ & $27(37.0)$ & 0.173 \\
Indication & Uterine myoma & $60(43.5)$ & $30(46.2)$ & $30(41.1)$ \\
& Adenomyosis & $24(17.4)$ & $11(16.9)$ & $13(17.8)$ \\
& Myoma+adenomyosis & $8(5.8)$ & $3(4.6)$ & $11(10.1)$ \\
& Cervical lesion & $19(13.8)$ & $8(12.3)$ & $12(11.6)$ \\
& Endometrial lesion & $22(15.9)$ & $10(15.4)$ & $2(2.7)$ \\
\hline
\end{tabular}

Values are presented as mean \pm standard deviation or number (\%).

SPA-LAVH, single-port access laparoscopic assisted vaginal hysterectomy; TPA-LAVH, three-port access laparoscopic assisted vaginal hysterectomy; BMI, body mass index. 
Table 2. Operative results

\begin{tabular}{|c|c|c|c|c|c|}
\hline \multirow{2}{*}{\multicolumn{2}{|c|}{ Operative characteristics }} & All $(n=138)$ & SPA-LAVH $(\mathrm{n}=65)$ & TPA-LAVH $(n=73)$ & $P$-value \\
\hline & & & & & \\
\hline \multicolumn{2}{|l|}{ Operating times (min) } & $94.3 \pm 25.0$ & $93.4 \pm 20.2$ & $95.1 \pm 28.7$ & 0.696 \\
\hline \multicolumn{2}{|c|}{ Hemoglobin changes (g/dL) } & $1.88 \pm 0.78$ & $1.91 \pm 0.68$ & $1.85 \pm 0.87$ & 0.667 \\
\hline \multicolumn{2}{|c|}{ Weight of resected uterus (g) } & $288.2 \pm 241.1$ & $261.7 \pm 205.3$ & $311.8 \pm 268.3$ & 0.225 \\
\hline \multicolumn{2}{|l|}{ Hospital stay (day) } & $6.1 \pm 1.4$ & $5.9 \pm 0.9$ & $6.4 \pm 1.6$ & 0.063 \\
\hline \multicolumn{2}{|l|}{ Pelvic adhesion } & $31(24.6)$ & $12(18.5)$ & $22(30.1)$ & 0.112 \\
\hline \multicolumn{2}{|c|}{ Using an additional trocar } & $1(0.7)$ & $1(1.5)$ & $0(0)$ & 0.471 \\
\hline \multicolumn{2}{|c|}{ Conversion to laparotomy } & $3(2.2)$ & $0(0)$ & $3(4.1)$ & 0.098 \\
\hline \multicolumn{6}{|l|}{ Complication } \\
\hline \multicolumn{2}{|c|}{ Blood transfusion during surgery } & $5(3.6)$ & $1(1.5)$ & $4(5.5)$ & 0.216 \\
\hline \multicolumn{2}{|c|}{ Blood transfusion after surgery } & $25(18.1)$ & $11(16.9)$ & $14(19.2)$ & 0.731 \\
\hline \multicolumn{2}{|c|}{ Bladder or uretreral injury } & $3(2.2)$ & $1(1.5)$ & $2(2.7)$ & 0.629 \\
\hline \multicolumn{2}{|l|}{ Bowel injury } & $0(0)$ & $0(0)$ & $0(0)$ & \\
\hline \multicolumn{2}{|l|}{ Postoperative fever } & $12(8.7)$ & $8(12.3)$ & $4(5.5)$ & 0.155 \\
\hline \multicolumn{6}{|l|}{ Results of operation } \\
\hline \multirow[t]{6}{*}{ Pathologic finding } & Uterine myoma & $48(34.8)$ & $21(32.3)$ & $27(37.0)$ & \\
\hline & Adenomyosis & $10(7.2)$ & $5(4.7)$ & $5(6.8)$ & \\
\hline & Myoma+adenomyosis & $44(31.9)$ & $22(33.8)$ & $22(30.1)$ & \\
\hline & Cervical lesion & $13(9.4)$ & $6(9.2)$ & $7(9.6)$ & \\
\hline & Endometrial lesion & $18(13.0)$ & $9(13.8)$ & $9(12.3)$ & \\
\hline & Others & $5(3.6)$ & $2(3.1)$ & $3(4.1)$ & \\
\hline \multirow[t]{5}{*}{ Concomitant surgery } & Unilateral OC & $23(62.3)$ & $8(12.3)$ & $15(20.5)$ & \\
\hline & Bilateral OC & $0(0)$ & $0(0)$ & $0(0)$ & \\
\hline & Unilateral oophorectomy & $0(0)$ & $0(0)$ & $0(0)$ & \\
\hline & Unilateral adnexectomy & $12(8.7)$ & $6(9.2)$ & $6(8.2)$ & \\
\hline & Bilateral adnexectomy & $17(12.3)$ & $6(9.2)$ & $11(15.1)$ & \\
\hline
\end{tabular}

Value are presented as mean \pm standard deviation or number (\%).

SPA-LAVH, single-port access laparoscopically assisted vaginal hysterectomy; TPA-LAVH, three-port access laparoscopically assisted vaginal hysterectomy; OC, ovarian cystectomy.

Table 3. Postoperative pain

\begin{tabular}{|lcccc|}
\hline Median VAS pain score & All $(\boldsymbol{n}=\mathbf{1 3 8})$ & SPA-LAVH $(\mathbf{n}=\mathbf{6 5})$ & TPA-LAVH $(\mathbf{n}=\mathbf{7 3})$ & $\boldsymbol{P}$-value \\
\hline Immediately & $3.64 \pm 0.82$ & $3.75 \pm 0.77$ & $3.54 \pm 0.85$ & 0.140 \\
$6 \mathrm{hr}$ & $2.66 \pm 0.72$ & $2.78 \pm 0.73$ & $2.56 \pm 0.71$ & 0.072 \\
$24 \mathrm{hr}$ & $1.89 \pm 0.59$ & $1.87 \pm 0.57$ & $1.90 \pm 0.60$ & 0.787 \\
$48 \mathrm{hr}$ & $1.54 \pm 0.56$ & $1.53 \pm 0.53$ & $1.54 \pm 0.58$ & 0.921 \\
\hline
\end{tabular}

Value are presented as mean \pm standard deviation.

VAS, visual analog scale; SPA-LAVH, single-port access laparoscopically assisted vaginal hysterectomy; TPA-LAVH, three-port access laparoscopically assisted vaginal hysterectomy.

쉽게 배꼽통로에 장착할 수 있는 장점이 있어 다른 방법에 비해 포트삽 입의 시간이 단축되는 장점이 있다고 저자들은 생각한다. 본 연구에서
수술시간은 평균 93분으로 삼공법 95분과 차이가 없었고, 다른 단일공 법 복강경하 질식자궁절제술에 대한 연구결과(87-122분)와도 큰 차이 


\title{
KOREAN JOURNAL OF OBSTETRICS \& GYNECOLOGY
}

\author{
KJOG Vol. 55, No. 1, 2012
}

Table 4. Patients' satisfaction

\begin{tabular}{|lccc|}
\hline Valuable & SPA-LAVH $(\mathbf{n}=65)$ & TPA-LAVH $(\mathbf{n}=\mathbf{7 3})^{\boldsymbol{P}_{\text {-value }}}$ \\
\hline Dissatisfactory & $1(1.5)$ & $5(6.8)$ & 0.127 \\
Not very satisfactory & $8(12.3)$ & $30(41.1)$ & 0.000 \\
Fairly satisfactory & $34(52.3)$ & $25(34.2)$ & 0.032 \\
Very satisfactory & $22(33.8)$ & $13(17.8)$ & 0.031 \\
\hline
\end{tabular}

Values are presented as number (\%).

SPA-LAVH, single-port access laparoscopically assisted vaginal hysterectomy; TPA-LAVH, three-port access laparoscopically assisted vaginal hysterectomy.

aBy the chi-square test.

는 없었다 $[5,6,8,13,16]$

본 연구에서는 환자의 나이, 체질량지수, 수술 과거력, 절제된 자궁무 게, 수술시간, 혈색소변화, 입원기간, 합병증 발생률, 수술 후 통증 등은 $P$ 값이 0.05 이상으로 통계학적 차이가 없었다. 또한 추가적인 포트의 삽입이 단일공법에서 1 예에서 있었고 개복술로의 전환은 삼공법에서 3 예에서 관찰되었으나 통계학적으로 유의하지 않았다.

단일공법 수술의 장점으로 배꼽에는 근육이 없고 총 피부절개 길이 가 감소되며 복벽 근육손상을 피할 수 있어 수술 후 통증감소를 보이 는데[17], Kim 등[5]의 보고에 따르면 단일공법 복강경하 질식자궁절제 술은 다공법에 비해 수술 24, 36시간 후 통증이 감소함을 보고하였고, Chen 등[6]의 보고에서는 수술 24, 48시간 후 통증이 감소하였고 수술 후 진통제 사용이 유의하게 감소함을 보고하였다. 그러나 본 연구에서 는 수술 후 진통제 사용을 조사하지 않았지만 위 보고와는 달리 수술직 후, 6시간, 24시간, 48시간 후 통증은 차이를 보이지 않았다.

단일공법 질식자궁절제술은 아니지만 단일공법 복강경하 담낭절제 술에서 환자 만족도를 평가한 연구들을 보면 다양한 만족도 결과가 보 고되고 있다. $\mathrm{CaO}$ 등[18] 주관적 만족도를 0 부터 100점까지 조사하여 단일공법군에서 91.2점으로 고시적 방법군 88.5에 비해 우수하다고 보 고하였으며, Aprea 등[19]은 수술 후 7일째 상처 만족도를 1부터 5점 까지 조사하여 단일공법군이 4.9점으로 고식적 방법군 3.5점에 비해 우수함을 보고하였지만, $\mathrm{Ma}$ 등[20]은 단일공법군과 고시적 방법군에서 환자 만족도가 차이가 없음을 보고하였다.

본 연구는 수술한 모든 환자들을 수술 6 주 후 외래에서 진찰하면서 수술에 대한 만족도를 조사한 자료를 분석하였다. 매우 만족과 만족은 단일공법군이 $33.8 \%$ 와 $52.3 \%$ 로 삼공법군의 $17.8 \%$ 와 $34.2 \%$ 에 비해 통계적으로 유의하게 높았다. 보통은 삼공법군에서 높았고, 불만족은 두 군 간에 통계학적 차이는 없었다. 환자 만족도는 수술 후 통증, 부작 용 발생률, 재원일수, 회복기간, 수술비용, 미용 효과 등이 영향을 미칠 수 있다. 하지만 본 연구에서는 환자 만족도에 영향을 주는 세부 요인 들에 대한 평가 없이 단순 만족도만을 조사했다는 한계점이 있지만 단 일공법군에서 절개부위가 배꼽 안으로 들어가 흉터가 보이지 않는 장 점 이외에 다른 요인들은 차이가 없어 아마도 단일공법의 뛰어난 미용 효과로 두 군 간 만족도 차이가 발생한 것으로 저자들은 생각한다.

비록 본 연구에서 수술방법이 환자의 선택으로 결정되었지만 수술방 법의 결정에 의사의 설명이 영향을 미칠수 있고 이러한 설명에 있어 환
자의 상태(자궁크기, 수술과거력, 체질량)에 따라 수술자의 편견이 있을 수 있는 한계가 있을 수 있다. 그러나 두 군 간의 체질량지수, 수술 과 거력, 분만력, 절제된 자궁 무게 등에 있어 통계학적 차이를 보이지 않 았다.

결론적으로 단일공법 복강경하 질식자궁절제술은 다공법과 비교하 여 수술 결과에 큰 차이는 없었고, 뛰어난 미용효과로 수술 후 만족도 가 높은 것을 본 연구를 토대로 알 수 있었다. 하지만 단일공법에서 환 자 만족도에 대한 정확한 평가를 위해서는 단순한 만족도 조사가 아닌, 만족도에 영향을 주는 요인들에 대한 세부적인 항목을 갖춘 대규모의 전향적 사례 대조군 연구가 필요할 것으로 생각한다.

\section{Acknowledgments}

이 논문은 2009년도 원광대학교 교비지원에 의해 수행됨.

\section{References}

1. Wu JM, Wechter ME, Geller EJ, Nguyen TV, Visco AG. Hysterectomy rates in the United States, 2003. Obstet Gynecol 2007;110:1091-5.

2. Brummer TH, Seppala TT, Harkki PS. National learning curve for laparoscopic hysterectomy and trends in hysterectomy in Finland 2000-2005. Hum Reprod 2008;23:840-5.

3. Pelosi MA, Pelosi MA 3rd. Laparoscopic hysterectomy with bilateral salpingo-oophorectomy using a single umbilical puncture. N J Med 1991;88:721-6.

4. Merchant AM, Cook MW, White BC, Davis SS, Sweeney JF, Lin E. Transumbilical Gelport access technique for performing single incision laparoscopic surgery (SILS). J Gastrointest Surg 2009:13:159-62.

5. Kim TJ, Lee YY, Cha HH, Kim CJ, Choi CH, Lee JW, et al. Singleport-access laparoscopic-assisted vaginal hysterectomy versus conventional laparoscopic-assisted vaginal hysterec- 


\section{KOREAN JOURNAL OF OBSTETRICS \& GYNECOLOGY}

Seong Nam Park, et al. Single-port laparoscopically assisted vaginal hysterectomy

tomy: a comparison of perioperative outcomes. Surg Endosc 2010;24:2248-52.

6. Chen YJ, Wang PH, Ocampo JO, Twu NF, Yen MS, Chao KC. Single-port compared with conventional laparoscopic-assisted vaginal hysterectomy: a randomized controlled trial. Obstet Gynecol 2011;117:906-12.

7. Jung WJ, Lee M, Yim GW, Lee SH, Paek JH, Kwon HY, et al. A randomized prospective study of single-port and four-port approaches for hysterectomy in terms of postoperative pain. Surg Endosc 2011;25:2462-9.

8. Lee JH, Choi JS, Jeon SW, Son CE, Hong JH, Bae JW. A prospective comparison of single-port laparoscopically assisted vaginal hysterectomy using transumbilical GelPort access and multiport laparoscopically assisted vaginal hysterectomy. Eur J Obstet Gynecol Reprod Biol 2011;158:294-7.

9. Revil SI, Robison JO, Rosen M, Hong MI. The reliability of a linear analogue for evaluating pain. Anaesthesia 1976;31:1191-8.

10. Voermans RP, Van Berge Henegouwen MI, Fockens P. Natural orifice transluminal endoscopic surgery (NOTES). Endoscopy 2007;39:1013-7.

11. Pelosi MA, Pelosi MA 3rd. Laparoscopic appendectomy using a single umbilical puncture (minilaparoscopy). J Reprod Med 1992;37:588-94.

12. Pelosi MA, Pelosi MA 3rd. Laparoscopic supracervical hysterectomy using a single-umbilical puncture (mini-laparoscopy). J Reprod Med 1992;37:777-84.

13. Park HS, Kim TJ, Song T, Kim MK, Lee YY, Choi CH, et al. Single-port access (SPA) laparoscopic surgery in gynecology: a surgeon's experience with an initial 200 cases. Eur J Obstet
Gynecol Reprod Biol 2011;154:81-4.

14. Kaouk JH, Haber GP, Goel RK, Desai MM, Aron M, Rackley RR, et al. Single-port laparoscopic surgery in urology: initial experience. Urology 2008;71:3-6

15. Desai MM, Stein R, Rao P, Canes D, Aron M, Rao PP, et al. Embryonic natural orifice transumbilical endoscopic surgery (E-NOTES) for advanced reconstruction: initial experience. Urology 2009;73:182-7.

16. Park BJ, Kim YW, Ro DY, Kim TE, Ryu KS, Kim JH. Evaluation of 110 cases of single-port access laparoscopically assisted vaginal hysterectomy (SPA-LAVH) and comparison with multi-port access. Korean J Obstet Gynecol 2010;53:633-9.

17. Ghezzi F, Cromi A, Colombo G, Uccella S, Bergamini V, Serati $M$, et al. Minimizing ancillary ports size in gynecologic laparoscopy: a randomized trial. J Minim Invasive Gynecol 2005;12:480-5.

18. Cao LP, Que RS, Zhou F, Ding GP, Jing DX. Transumbilical single-port laparoscopic cholecystectomy using traditional laparoscopic instruments: a report of thirty-six cases. J Zhejiang Univ Sci B 2011;12:862-6.

19. Aprea G, Coppola Bottazzi E, Guida F, Masone S, Persico G. Laparoendoscopic single site (LESS) versus classic video-laparoscopic cholecystectomy: a randomized prospective study. J Surg Res 2011;166:e109-12.

20. Ma J, Cassera MA, Spaun GO, Hammill CW, Hansen PD, Aliabadi-Wahle $S$. Randomized controlled trial comparing singleport laparoscopic cholecystectomy and four-port laparoscopic cholecystectomy. Ann Surg 2011;254:22-7. 


\section{KOREAN JOURNAL OF OBSTETRICS \& GYNECOLOGY}

KJOG Vol. 55, No. 1, 2012

\section{SILS 포트를 이용한 단일공법 복강경하 질식자궁절제술과 삼공법 복강경하 질식자궁절제술의 비교}

원광대학교 의과대학 ${ }^{1}$ 산부인과학교실, ${ }^{2}$ 마취통증의학교실

박성남', 홍기연, 김훈영, 김병륜 ${ }^{1}$, 이 철²

목적

SLLS포트를 이용한 단일공법 복강경하 질식자궁절제술을 수술 결과들과 환자 만족도 측면에서 삼공법과 비교하기 위함이다.

연구방법

2010년 4월부터 2011년 5월까지 원광대학교병원에서 자궁경부와 자궁체부의 양성질환으로 복강경하 질식자궁절제술을 시행받은 총 138 명의 환자를 대상으로 하였다. 각각의 수술법은 환자 동의 아래 직접 선택하였고, SLLS을 이용한 단일공법 복강경하 질식자궁절제술이 시행된 환자 65명과, 삼공법으로 시행된 환자 73 명이 대상이 되었다.

결과

수술시간(93.4 \pm 20.2 분 vs. $95.1 \pm 28.7$ 분, $P=0.696)$, 혈색소변화 $(1.91 \pm 0.68 \mathrm{~g} / \mathrm{dL}$ vs. $1.85 \pm 0.87 \mathrm{~g} / \mathrm{dL}, P=0.667)$, 절제된 자궁 무 게(288.2 $\pm 241.1 \mathrm{~g}$ vs. $311.8 \pm 268.3 \mathrm{~g}, P=0.225)$, 재원기간(5.9 \pm 0.9 일 vs. $6.4 \pm 1.6$ 일, $P=0.063)$, 추가적인 포트삽입(1.5\% vs. $0 \%$, $P=0.471$ ), 개복술로의 전환(0\% vs. 4.1\%, $P=0.098$ ), 수술 후 통증(시각통증등급)은 두 군 간에 유의한 차이를 보이지 않았다. 하지만 수술 6 주 후 조사된 환자 만족도는 단일공법군이 만족(52.3\% vs. 34.2\%, $P=0.032)$ 과 매우 만족(33.8\% vs. $17.8 \%, P=0.031)$ 에서 통계학적으 로 유의하게 높았다.

결론

SILS포트를 이용한 단일공법 복강경하 질식자궁절제술은 복강경하 질식자궁절제술을 시행받는 환자에서 삼공법 복강경하 질식자궁절제 술에 견줄만한 방법이며, 환자 만족도 측면에서는 삼공법 복강경하 질식자궁절제술에 비해 우수하다.

중심단어: 단일공법, 삼공법, 복강경하 질식자궁절제술, 환자 만족도 